\title{
Design of Bilateral Switched Reluctance Linear Generator to Convert Wave Energy: Case Study in Sicily
}

\author{
V. Di Dio ${ }^{1, a}$, V. Franzitta ${ }^{1, b}$, D. Milone ${ }^{1, c}$, S. Pitruzzella ${ }^{2, d}$ M. Trapanese ${ }^{1, e}$, \\ A.Viola ${ }^{1, f}$.
}

${ }^{1}$ DEIM -Dipartimento Di Energia, Ingegneria Dell'informazione, E Modelli Matematici, University of Palermo, Palermo 90128, Italy

${ }^{2}$ Facoltà di Architettura Università degli Studi Palermo, Viale delle Scienze 14, Palermo 90128, Italy

a vincenzo.didio@unipa.it , b franzitta@dream.unipa.it, ${ }^{c}$ daniele.milone@unipa.it, d salvatore.pitruzzella@unipa.it, ${ }^{e}$ marco.trapanese@unipa.it ,, alessia.viola@unipa.it,

Keywords: reluctance generator, energy, emf, FEM simulation.

\begin{abstract}
The aim of this work is a case study of the adaptation bilateral switched reluctance linear generator to the exploitation of energy of the sea. This type of generator can be used to convert wave energy in electrical energy.

In this paper we present an analytical sizing and FEM simulation. As for the results, analysis of the data extracted through the simulations it was possible to calculate the emf. The emf was calculated in two cases of motion of the slider: first hypothesis has set the constant speed while the second is a variable speed according to the law of an oscillatory motion of the sea.
\end{abstract}

\section{Introduction}

Sicily (Italy) is the largest island in the Mediterranean Sea and the use of wave energy is developing.

Wave energy represents the "new entry" in the extensive green energy discussion and has been recognised by the international community as a renewable energy source with the potential to contribute to the electricity market. [1]

Considerable works have been undertaken on wave energy assessment in several areas of the European coastline. The total wave power was found to range from $1 \mathrm{GW}$ in Sweden, to $120 \mathrm{GW}$ in UK, passing through 3.4 GW of Denmark, $10 \mathrm{GW}$ in Portugal, $21 \mathrm{GW}$ in Ireland and over $28 \mathrm{GW}$ in the area of Gulf of Gascoigne, France Recent works focused on the Spanish coastline reveal an enormous potential in several coastal areas facing the Atlantic, with a wave power which frequently reaches $200 \mathrm{MWh} / \mathrm{m}$ and exceeds $400 \mathrm{MWh} / \mathrm{m}$ along the Death Coast.[2-3]

Public concerns on environmental issues have stimulated an ever increasing effort on harvesting renewable energies. Among them, several approaches to harvest sea wave energy have been proposed; almost all of them introduce a mechanical conversion device between the waves and the electromagnetic generator.

To generate a substantial amount of power, Wave Energy Converters have been proposed.

Several solutions have been discussed, some consider a single energy absorber others consider several absorbing unit. In this paper it is adopted a procedure to design a Bilateral Switched Reluctance Linear Generator. The operative conditions represent the mean wave motion of Tirreno Sea (real environment of this project)[4].

Description and sizing of generator. The Switched Reluctance linear machine system has the advantages in simple and firm structure with no brush, no winding and no permanent magnet, no "direct-short-circuit" fault on the power converter, the strong mechanical intensity and high fault tolerant capability. It has the good application prospect on oceanic tidal and wave energy linear generator system. 
The principle of the Switch Reluctance linear generator is same to that of Switched Reluctance rotary generator, which is the total magnetic flux is closed along the path with least reluctance, making the magnetic distorted so that it can generate electromagnetic force in tangential direction[5-6].

Generally, the design of Switched Reluctance linear generator should be accomplished by analogy analysis between Switched Reluctance rotary generator and Switched Reluctance linear generator, and the modifications depending on its special characteristics. A design method similar with the design of rotary generator, is used in this example[1].

According to the Switched Reluctance linear generator application, the dimensions of the prototype of LSRM are:

- linear density of the stator current is $100000 \mathrm{~A} / \mathrm{m}$;

- Magnetic Field is B 0.25 T;

- Rated velocity is $\mathrm{v} 1 \mathrm{~m} / \mathrm{s}$;

- Output Power is $1000 \mathrm{~W}$.

We report below a drawing with all the geometrical dimensions.

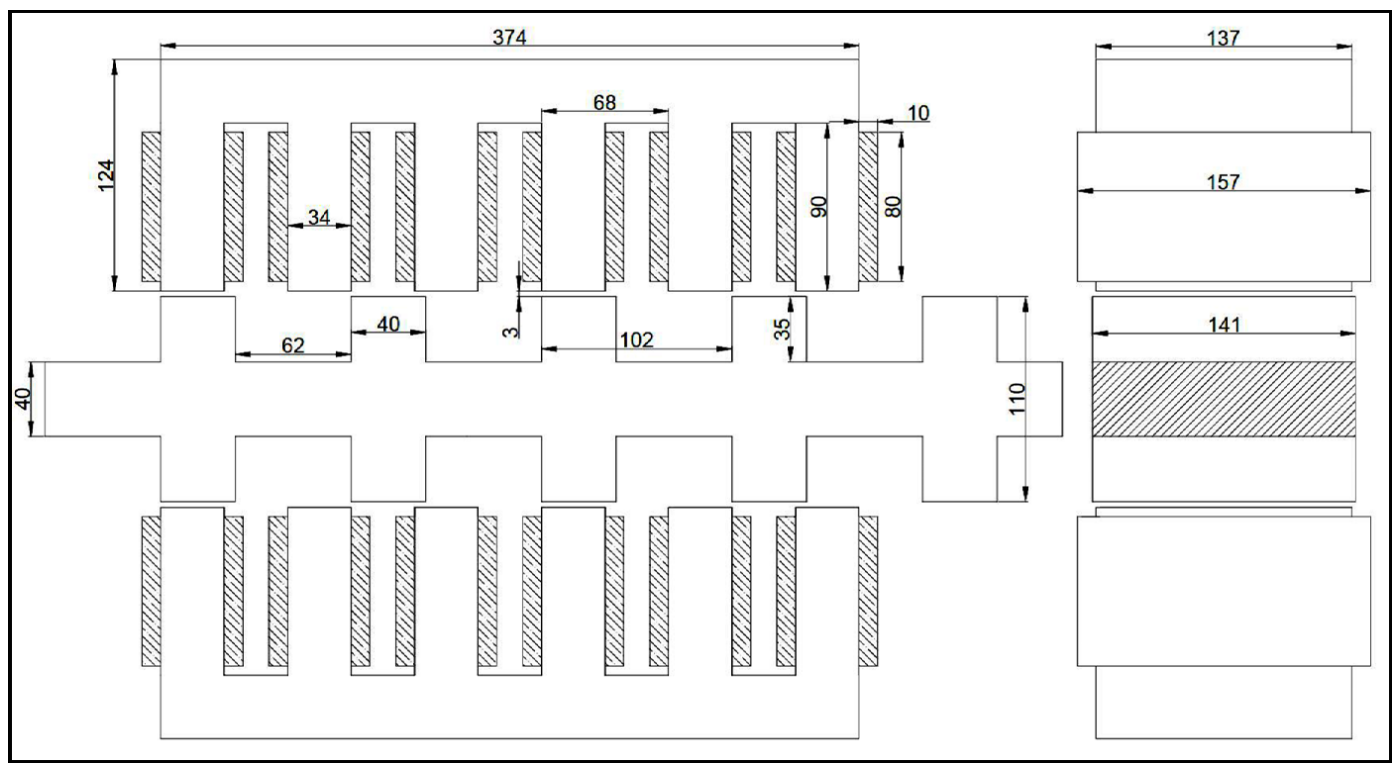

Figure 1. Prototype LSRM

Case Study: Simulation and Results. In this part of the paper we describe the procedure adopted after the sizing of the generator: simulation with FEM software and evaluation of emf in different case of motion of the slider

The simulation was be made in 2D geometry to obtain a visualization of Magnetic Field B.

The choice of materials used is iron to the stator and copper to the windings. To complete it, it's necessary to define the boundary condition: insulating condition.[7-8]

The set of fixed parameters are:

- Number of spire 200;

- Temperature is 293.15 [K];

- Excitation is direct current;

- Rated Current is I 10 [A].

The figures 2 and 3 represent two conditions: a) the tooth is aligned with the tooth of the stator and B) when the position aligns with the next tooth of the stator 


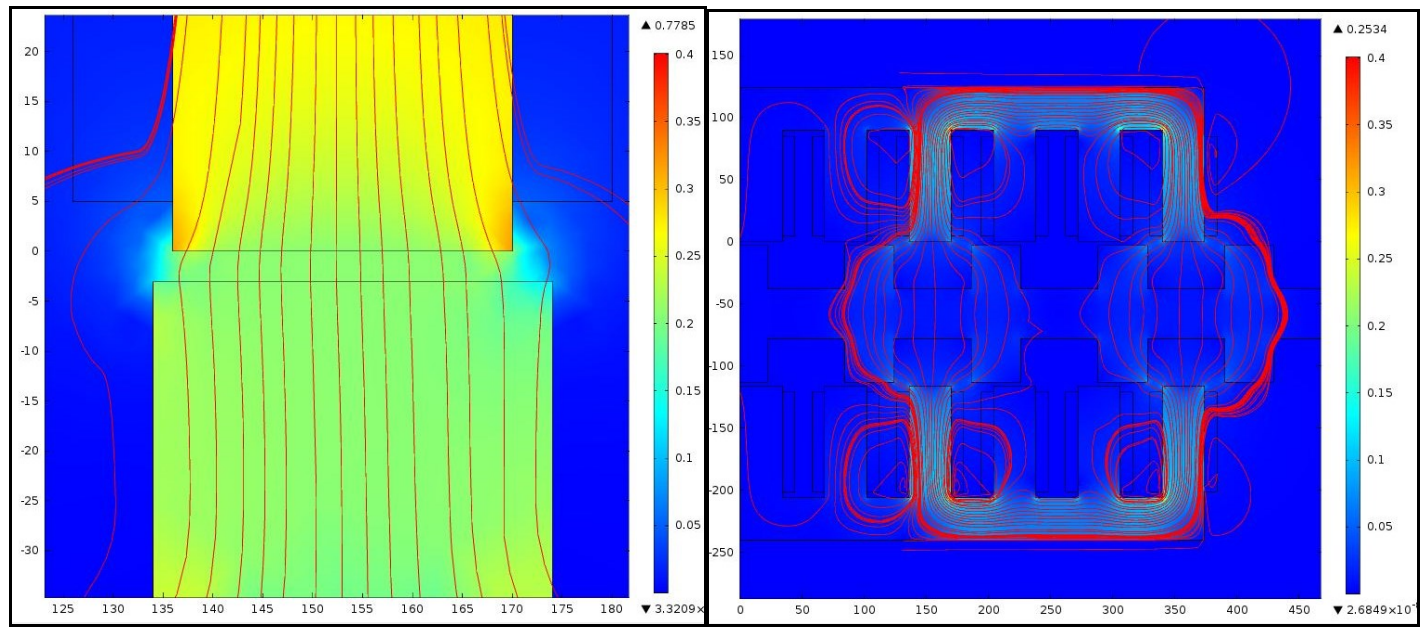

Figure 2 For alignment position: Values of the magnetic induction field and Flow lines

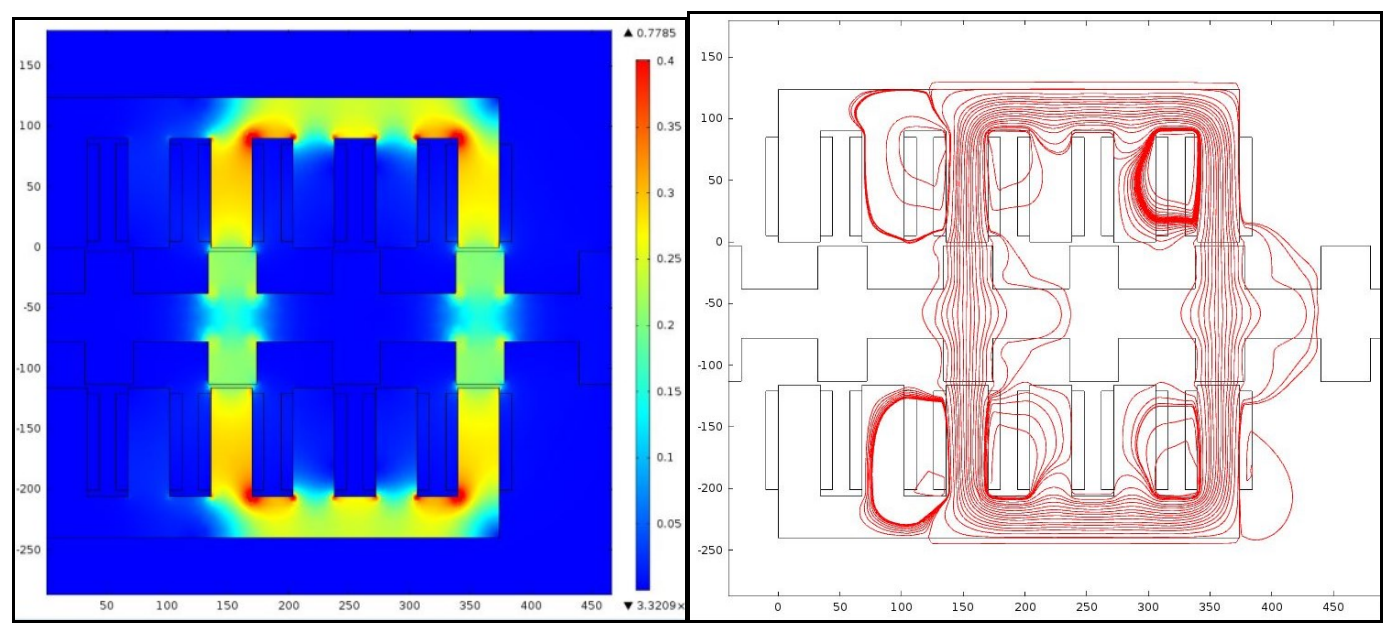

Figure 3. For not alignment position: Values of the magnetic induction field and Flow lines of air gap

The results obtained are important to calculate the values of the flux linkage with the coils. Using this results, it is been possible to derive emf [9].

The first case is when the motion of slider is linear:

$y=y_{0}+v t$ with $v$ is constant.

The second hypothesis is oscillatory motion:

$$
y=y_{0}+H \operatorname{sen}(\omega t) .
$$

If we suppose the condition of linear motion, the velocity is fixed to the value of $1 \mathrm{~m} / \mathrm{s}$. Fem can be obtained using the equation 3 :

$$
\text { e.m.f }=-(2 F v) / i
$$

where $\mathrm{F}$ is the electromagnetic force and $\mathrm{i}$ is the current. 


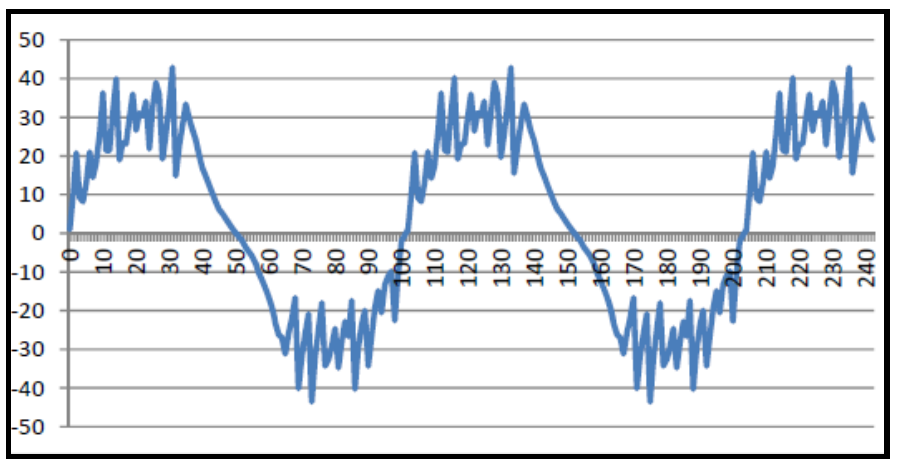

Figure 3. Course of the induced electromotive force (eq.3)

In the second case the emf was calculated according to Faraday's law in which it is placed Nspire $=$ 200 and for the flow values obtained by the simulation:

$$
\text { f.e.m }=-N_{\text {spire }} \mathrm{d} \Phi / \mathrm{dt}
$$

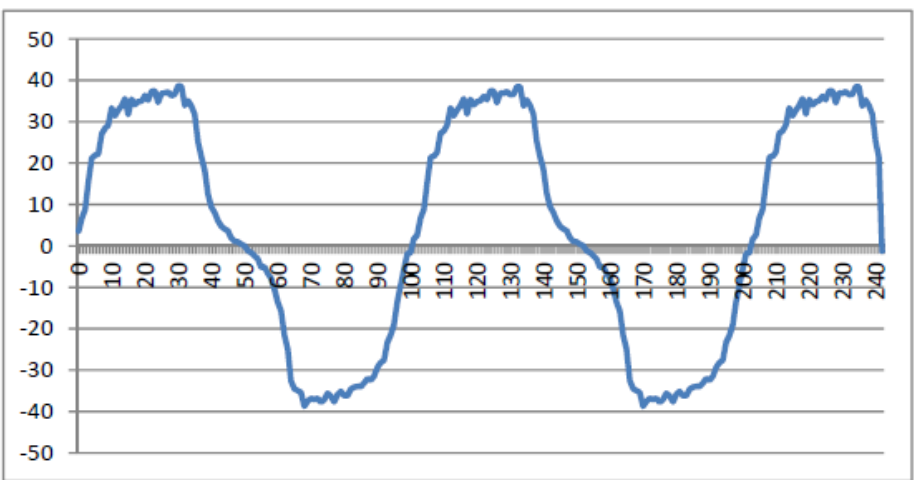

Figure 4. Course of the induced electromotive force (eq.4)

In this second hypothesis it is assumed that the slider is connected mechanically to a buoy subject to wave motion and therefore follow the following law of motion:

$$
y=y_{0}+H \operatorname{sen}(\omega t) .
$$

As amplitude values $\mathrm{H}$ and pulsation $\omega$ were applied the average values data of the buoy measure waves of Capogallo (Palermo). In particular, the values are:

- $\mathrm{H}=1 \mathrm{~m}$

- $\mathrm{T}=4 \mathrm{~s}, \omega=2 \pi / \mathrm{T}=1.57 \mathrm{rad} / \mathrm{s}$ 


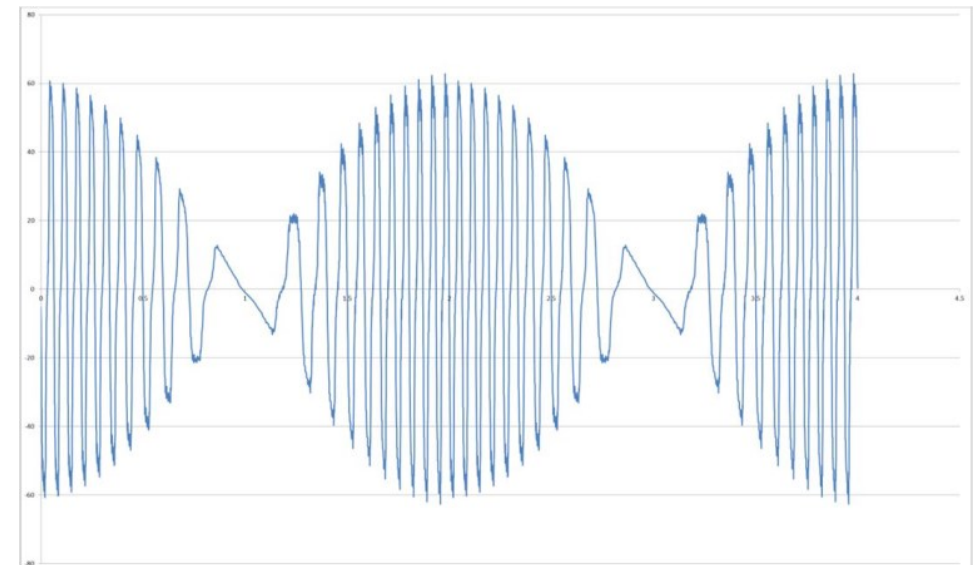

Figure 5. Performance of the emf in the case of oscillatory motion (eq.5)

Conclusions. In this paper we can say that the generator has great potential in this field of application, especially with respect to the permanent magnet generator, Indeed, it presents the advantage of having a cost considerably reduced just for the fact of no use for the magnetization of the magnet permanent.

However it is necessary for its operation a electronic circuit power supply and control that surely makes the machine more complex, decreasing the reliability and autonomy since the phases must always be electrically powered.

Acknowledgment. This work was funded by Ministero dell' Ambiente e Del Mare through IMPETUS project.

\section{References}

[1] H. Chen, X. Wang, J. J. Gu, S. Lu, Design of Bilateral Switched Reluctance Linear Generator . 2010 IEEE Electrical Power \& Energy Conference 978-1-4244-8188-0/10 (2010)

[2] M. Trapanese, V. Franzitta, , A Viola. The Jiles Atherton Model for Description Of Hysteresis in Lithium Battery. Conference Proceedings - IEEE Applied Power Electronics Conference and Exposition - APEC 2013- Long Beach,(CA), March 2013-978-1-4673-4355-8, pp 2773-2775

[3] M. Trapanese, V. Franzitta, A Viola. Design and Performance of a High Temperature Superconducting Axial Flux Generator. IEEE Transactions on Magnetics, Vol. 49, issue 7, pp 4113-4115.

[4] M. Trapanese, V. Franzitta, A Viola. Energy and Economic Analysis of Different Buildings Constructed with Environmentally Sustainable and Traditional Materials. Applied Mechanics and Materials, Vol.432 (2013) pp 109-114.

[5] GL Rocca, V Franzitta, A Viola, M Trapanese. Dynamic Preisach Hysteresis Model for Magnetostrictive Materials for Energy Application. Applied Mechanics and Materials, Vol.432 (2013) pp 72-77.

[6] V Franzitta, A Viola, M Trapanese. Design and Test of a Thermomagnetic Motor Using a Gadolinium Rotor, Vol.432 (2013) pp 324-329.

[7] A Viola, M Trapanese, V Franzitta. Evaluation of the Potential Energy from Wave Motion on the Sicilian coast. Conference Proceedings - OCEANS - Bergen, 2013 MTS/IEEE, Bergen, June 2013-978-1-4799-0002-2/13.

[8] V Franzitta, M Trapanese, C Giaconia, P Ferrara, A Viola. Design and experimental test of a low costweather buoy. Conference Proceedings - OCEANS - Bergen, 2013 MTS/IEEE, Bergen, June 2013-978-1-4799-0002-2/13.

[9] M Trapanese, V Franzitta, A Viola, E Napoli, V Mamola. Numerical simulation of a wawe generator: a case of study.. Conference Proceedings - OCEANS - Bergen, 2013 MTS/IEEE, Bergen, June 2013-978-1-4799-0002-2/13. 


\section{Energy Development}

10.4028/www.scientific.net/AMR.860-863

Design of Bilateral Switched Reluctance Linear Generator to Convert Wave Energy: Case Study in Sicily

10.4028/www.scientific.net/AMR.860-863.1694 